\title{
Positioning and Applications for Planet Earth
}

\author{
S. Verhagen, G. Retscher, M.C. Santos, X. L. Ding, Y. Gao, and S.G. Jin
}

\begin{abstract}
GNSS, InSAR and LIDAR are identified as important techniques when it comes to monitoring and remote sensing of our planet Earth and its atmosphere. In fact, these techniques can be considered as key elements of the Global Geodetic Observing System. Examples of applications are: environmental monitoring; volcano monitoring, land slides, tectonic motion, deforming structures, atmosphere modeling, and ocean remote sensing. Hence, it concerns applications at local and regional scales, as well as at global scales. The main issues can be summarized as: need for a better understanding of processes, leading to better models; need for observational material; and adequate modeling techniques.
\end{abstract}

\subsection{Introduction}

Recognising the central role that Global Navigation Satellite Systems (GNSS) play in many applications like engineering, mapping and remote sensing, the work of Commission 4 of the International

S. Verhagen $(\bowtie)$

DEOS, Delft University of Technology, Delft, The Netherlands e-mail: a.a.verhagen@tudelft.nl

G. Retscher

Vienna University of Technology, Vienna, Austria

M.C. Santos

University of New Brunswick, Fredericton, NB, Canada

X.L. Ding

Hong Kong Polytechnic University, Hung Hom, Kowloon, Hong Kong

Y. Gao

University of Calgary, Calgary, AB, Canada

S.G. Jin

Center for Space Research, University of Texas, Austin, TX, USA
Association of Geodesy (IAG) focuses on several GNSS-based techniques, taking into account GPS, Glonass, Galileo and Beidoe. These techniques include precise positioning, but extending beyond the applications of reference frame densification and geodynamics, to address the demands of precise, real-time positioning of moving platforms.

Precise kinematic GNSS positioning technology itself (alone or in combination with other positioning sensors) is a key topic as well as its applications in surveying and engineering. Recognising the role of continuously operating GPS reference station network, the non-positioning applications of such geodetic infrastructure is considered as well, such as atmospheric sounding.

The commission also deals with geodetic remote sensing, using (differential) InSAR, and GNSS as a remote sensor with land, ocean and atmosphere applications.

This contribution aims to summarize the most important applications of GNSS, InSAR and LIDAR in the field of monitoring and remote sensing of our 
planet Earth and its atmosphere, either at local or regional scales or even at a global scale. The techniques can be considered as key elements of the Global Geodetic Observing System (GGOS), which is the flagship of IAG (Drewes 2007).

\subsection{Geotechnical and Structural Engineering}

\subsubsection{Monitoring and Alert Systems for Local Geodynamic Processes}

Nowadays extended multi-sensor deformation measurement systems consisting of terrestrial geodetic and geotechnical measurement as well as hydrological and meteorological instrumentation completed by the InSAR technique are mainly employed for multi-scale monitoring of landslide prone areas. Thereby InSAR is used for large-scale detection of landslide prone areas as well as for deformation measurements of the investigated landslide area.

Such a complete measurement system is very suitable for the investigation of the kinematic behaviour of landslides and together with other (e.g. hydrological, meteorological, etc.) parameters for the study of the dynamics of landslides (Mentes 2008a). The observation data is usually collected in GIS (see e.g. Lakakis et al. 2009b; Mentes 2008a, b) and used to develop Spatial Decision Support Systems (SDSS) (e.g. Lakakis et al. 2009a) and Early warning systems.

The Dunaföldvár test site in Hungary is monitored by terrestrial and InSAR measurement techniques. Figure 88.1 show the test site before and after the
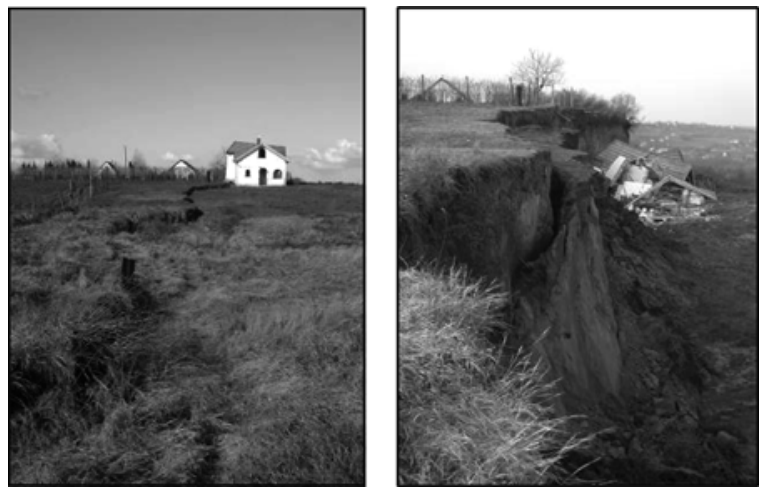

Fig. 88.1 Beginning of landslide in 2007 (left), and landslide after February 12, 2008 (right) landslide on February 12, 2008. The high bank on this area was sliding slowly with increasing velocity since September of 2007 till 12 of February 2008. On this day there was an abrupt sliding. About $500,000 \mathrm{~m}^{3}$ loess was sliding toward to the river Danube. The whole sliding process was monitored. The study of the movement is a good possibility to understand the kinematics and dynamics of the slope. The monitoring will be continued in the future to study the aftersliding processes (Újvári et al. 2008, 2009).

\subsubsection{Application of Artificial Intelligence in Engineering Geodesy}

In the last years, Artificial Intelligence (AI) has become an essential technique for solving complex problems in Engineering Geodesy. AI is an extremely broad field - the topics range from the understanding of the nature of intelligence to the understanding of knowledge representation and deduction processes, eventually resulting in the construction of computer programs which act intelligently. Especially the latter topic plays a central role in applications (Reiterer and Egly 2008). Current applications using AI methodologies in engineering geodesy are:

- Geodetic data analysis

- Deformation analysis

- Navigation

- Deformation network adjustment

- Optimization of complex measurement procedures An example highlighted in the following is a new deformation analysis system based on AI techniques. Here AI shall be used for the task of deformation assessment and deformation interpretation. The main task of the AI component is to transfer the information of a deformation analysis in a useable form for an automatic deformation interpretation. Therefore different approaches from the AI field are used and joined to a case-based reasoning system. The simplified measurement and analysis procedure, including the deformation assessment component is shown in Fig. 88.2. Although this deformation assessment is mainly developed for a terrestrial laser scanner and imagebased measurement system, an extension to other data acquisition systems is possible. The deformation assessment developed at the Vienna University of Technology is based on the idea of supporting the expert who performs the interpretation by former 


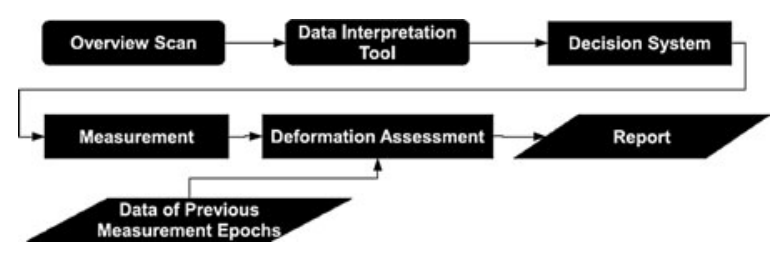

Fig. 88.2 Simplified system architecture of the deformation assessment component (after Lehmann et al. 2007)

deformation cases. The case base includes the reason for the former deformations (Lehmann and Reiterer 2008).

\subsection{Modelling and Remote Sensing of the Atmosphere}

\subsection{1 lonosphere}

The past years have seen an increasing effort in the collection of experimental data for monitoring of TEC and ionospheric scintillation studies. This effort has resulted in the deployment of dedicated networks of ground GNSS and scintillation receivers, at high and mid latitudes. One of such networks is the Canadian High Arctic Ionospheric Network (CHAIN) composed of GPS receivers collocated with ionosondes. This configuration of instruments (collocated ionosondes and GPS receivers) will have an added advantage in the tomographic imaging of the electron density structures in the polar cap and calibration of the GPS data (Jayachandran et al. 2009). Similar effort is taking place in the Antarctica (Alfonsi et al. 2008). Other networks exist. There is also effort by means of satellite missions. For example, in situ measurements from GRACE K-Band ranging and CHAMP planar Langmuir probe (PLP) have been used for the validation of the International Reference Ionosphere (IRI); and FORMOSAT-3/COSMIC occultation data used in combination with GNSS and satellite altimetry aiming at a combined global VTEC model (Jakowski et al. 2007; Alizadeh et al. 2008; Todorova et al. 2008; Mayer and Jakowski 2009).

There has been effort put on enhancements in the spatial and temporal representation of TEC and or VTEC, globally, regionally or locally. Algorithms for spatial representation are a function of the area size and can be spherical harmonics, trigonometric B-splines, endpoint-interpolating B-splines, Chapman functions. For the temporal representation, there is a choice among empirical orthogonal functions, B-splines and Fourier series representation. An a-priori regularization procedure is usually needed to handle existing data gaps, even though multivariate adaptive regression splines have been shown to be capable of dealing with rare observations without regularization (Schmidt et al. 2007, 2008).

Near- and real-time applications require the dissemination of predicted values of TEC. This brings to mind the SBAS (WAAS, MSAS and EGNOS, the later has just made available its "Open Service"), based on continental networks but regional or local systems may also support these applications.

Investigation into multi-GNSS constellation and higher order (e.g., 3rd) determination TEC seem to be gaining momentum. Higher order ionospheric delay terms, which have been mostly disregarded in the dual-frequency world, can be taken into account in a multi-frequency reality. The $\mathrm{cm}$-level contribution of the ionospheric 2nd and 3rd order terms (in the cubic and quadratic inverse of the frequencies) can be more easily modelled in a triple- (or multi-) frequency system (Hoque and Jakowski 2008). The inclusion of higher order ionospheric terms in GNSS processing can potentially lead to an increase in accuracy at a global level by a few millimetres (HernándezPajares et al. 2007).

\subsubsection{Troposphere}

The increasing use of Numerical Weather Models (NWM) has helped enhancing the prediction of neutral atmospheric models (Boehm et al. 2006). It has also become a source of neutral atmospheric delay that can be directly applied in GNSS processing, including PPP (Hobiger et al. 2008a). If from one side NWMs contain a more realistic temporal representation of the delay than prediction models, from the other side the extraction of this information requires ray-tracing through the neutral atmosphere, a time consuming task if done properly (Nievinski 2009). Fast and accurate algorithms are of fundamental necessity (Hobiger et al. 2008b). How can NWM be used in practice 
vis-à-vis computational cost "vs." accuracy? Is it necessary to extract all information contained in a NWM to obtain a more accurate delay than that provided by prediction models, especially at low elevation angles? These still seem to be open questions.

There has been an increasing emphasis of neutralatmosphere delay monitoring by ground GNSS and satellite missions, with radio occultation consolidating itself as a solid technique (Wickert et al. 2009).

There is a continuing effort towards enhancements in the spatial and temporal representation of the neutral-atmosphere including its azimuthal asymmetry. Several models incorporating gradients, spherical harmonics, tomography, have been further tested including information from NWMs (Urquhart et al. 2011; Ghoddousi-Fard et al. 2009; Rohm and Bosy 2009). The theory of turbulence seems to have gained more attention recently in the modeling of GNSS observations either at functional or stochastic levels (Schön and Brunner 2008; Nilsson et al. 2009).

\subsection{Applications of Satellite and Airborne Imaging Systems}

Synthetic Aperture Radar (SAR) and Light Detection And Ranging (LiDAR) systems are very useful for geodetic applications, such as monitoring local area ground surface deformations due to volcanic and seismic activities, and ground subsidence associated with city development, mining activities (e.g. Ge et al. 2007; $\mathrm{Ng}$ et al. 2008), ground liquid withdrawal, and land reclamation (e.g. Ding et al. 2004).

InSAR is a very active field of research in the geodetic research communities. The current research issues include the development of more effective methods/ algorithms for InSAR solutions, the quality control and assurance of InSAR measurements, the study and mitigation of biases in InSAR measurements such as the atmospheric effects (e.g. Li et al. 2006), integration of InSAR and other geodetic technologies such as GPS, and new and innovative applications of the technology in geodetic studies (Fig. 88.3).

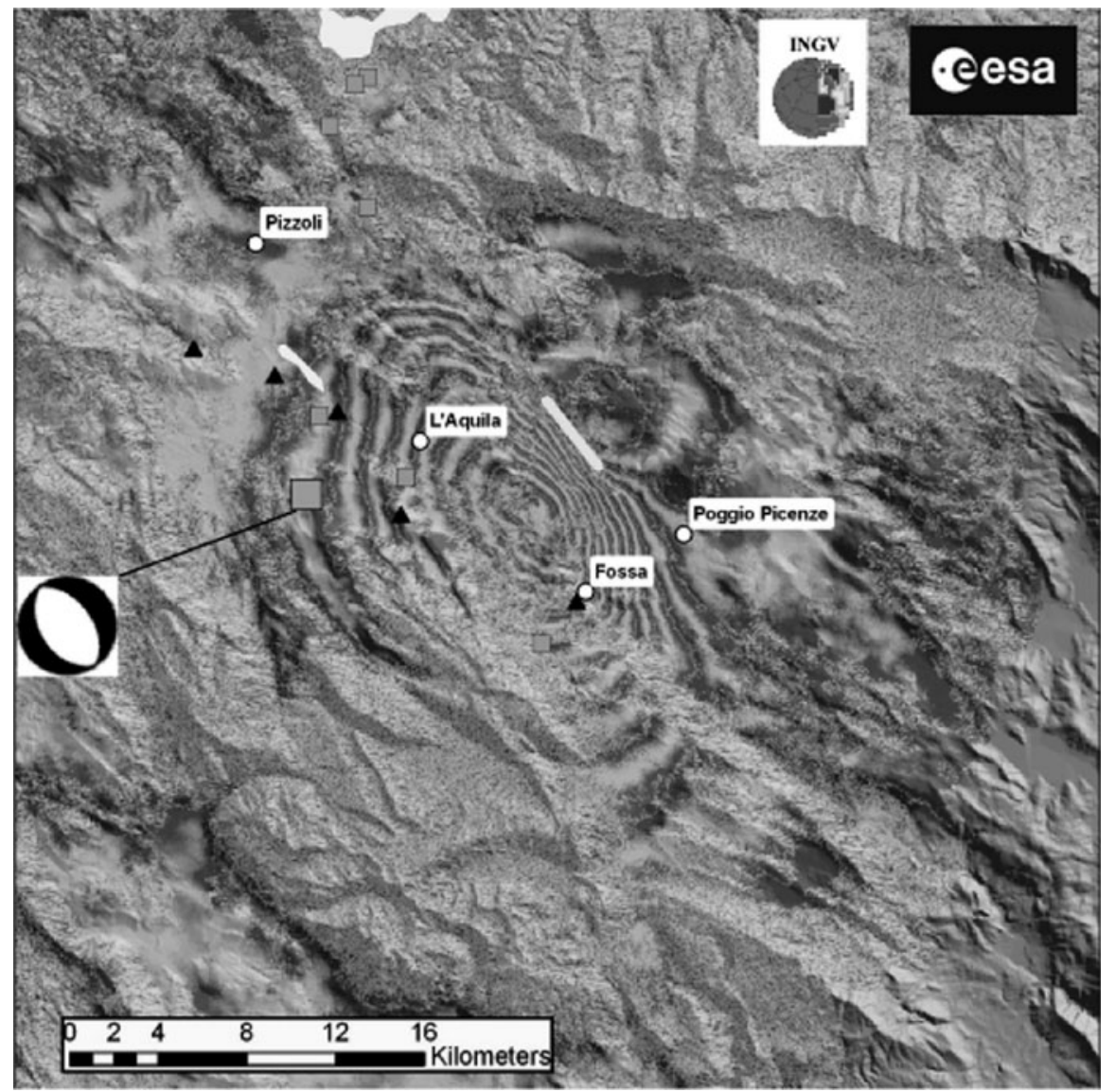

Fig. 88.3 Deformation observed with InSAR after earthquake in L'Aquila, Italy on 6 April 2009 with magnitude of 6.3 


\subsection{GNSS Reflectometry}

The signals of Global Navigation Satellite Systems (GNSS), including US Global Positioning System (GPS), Russia GLONASS, Europe Galileo and China Compass, propagate the atmosphere with the delay and reach users with the multipath error. For a long time, such indirect GNSS signals are considered as a nuisance, i.e. error sources, and now can be transferred into useful products, e.g. the water vapor, temperature, and pressure, electron density of the atmosphere and surface characteristics of land and oceans (Jin and Komjathy 2010).

Surface multipath delay from the GNSS signal reflecting from the sea and land surface, could be used as a new tool in ocean, coastal, wetlands, Crater Lake, landslide, soil moisture, snow and ice remote sensing (e.g. Komjathy et al. 2004). Together with information on the receiving antenna position and the medium, associating with the surface properties of the reflecting surface, the delay measurement can be used to determine such factors as wave height, wind speed, wind direction, and even sea ice conditions. MartinNeira (1993) first proposed and described a bistatic ocean altimetry system utilizing the signal of GPS. Recently, a number of applications have been implemented using GPS signals reflected from the ocean surface, such as determining wave height, wind speed and wind direction of ocean surface, ocean eddy, and Sea surface conditions (Rius et al. 2002; Komjathy et al. 2004; Gleason et al. 2005). The estimated wind speed using surface-reflected GPS data is consistent with independent wind speed measurements derived from the TOPEX/Poseidon altimetry satellite and Balloon at the level of $2 \mathrm{~m} / \mathrm{s}$, and the estimated wind direction using surface-reflected GPS data is almost consistent with results obtained from a buoy at the level of $10^{\circ}$ (Garrison et al. 2002; Komjathy et al. 2004).

Acknowledgements This contribution is the result of a collaborative effort of IAG Commission 4.

See: http://enterprise.lr.tudelft.nl/iag/iag \_comm4.htm.

The research of Sandra Verhagen is supported by the Dutch Technology Foundation STW, applied science division of NWO and the Technology Program of the Ministry of Economic Affairs.

\section{References}

Alfonsi L, Kavanagh E, Amata P, Cilliers E, Correia E, Freeman M, Kauristie K, Liu R, Luntama J-P, Mitchell CN, Zherebtsov GE (2008) Probing the high latitude ionosphere from ground-based observations: the state of current knowledge and capabilities during IPY (2007-2009). J Atmos Solar Terr Phys 70(18):2293-2308

Alizadeh MM, Schuh H, Todorova S, Schmidt M (2008) Towards 4D ionosphere model combining GNSS and satellite altimetry with Formosat-3/COSMIC. Geodetic Week, Bremen

Boehm J, Niell A, Tregoning P, Schuh H (2006) Global mapping function (GMF): a new empirical mapping function based on numerical weather model data. Geophys Res Lett 33:L07304. doi:10.1029/2005GL025546

Ding XL, Liu GX, Li ZW, Li ZL, Chen YQ (2004) Ground settlement monitoring in Hong Kong with satellite SAR interferometry. Photogramm Eng Remote Sens 70(10):1151-1156

Drewes H (2007) Science Rationale of the Global Geodetic Observing System (GGOS). International Association of Geodesy Symposia, 2007, Volume 130, Part VI, 703-710, doi: 10.1007/978-3-540-49350-1_101

Garrison JL, Komjathy A, Zavorotny VU, Katzberg SJ (2002) Wind speed measurement from forward scattered GPS signals. IEEE Trans Geosci Remote Sens 40(1):50-65

Ge L, Chang H-C, Rizos C (2007) Mine subsidence monitoring using multi-source satellite SAR images. Photogramm Eng Remote Sens 73(3):259-266

Ghoddousi-Fard R, Dare P, Langley RB (2009) Tropospheric delay gradients from numerical weather prediction models: effects on GPS estimated parameters. GPS Sol 13:281-291

Gleason S, Hodgart S, Sun Y, Gommenginger C, Mackin S, Adjra M, Unwin M (2005) Detection and processing of bistatically reflected GPS signals from low earth orbit for the purpose of ocean remote sensing. IEEE Trans Geosci Remote Sens 43(6):1229-1241

Hernández-Pajares M, Juan JM, Sanz J, Orús R (2007) Secondorder term in GPS: implementation and impact on geodetic estimates. J Geophys Res 112:B08417 (a correction appeared in Vol. 113, B06407)

Hobiger T, Ichikawa R, Takasu T, Koyama Y, Kondo T (2008a) Ray-traced troposphere slant delays for precise point positioning. Earth Planets Space 60(5):e1-e4

Hobiger T, Ichikawa R, Kondo T, Koyama Y (2008b) Fast and accurate ray-tracing algorithms for real-time space geodetic applications using numerical weather models. J Geophys Res 113(D203027):1-14

Hoque MM, Jakowski N (2008) Estimate of higher order ionospheric errors in GNSS positioning. Radio Sci 43:RS5008. doi:10.1029/2007RS003817

Jakowski N, Wilken V, Mayer C (2007) Space weather monitoring by GPS measurements on board CHAMP. Space Weather 5:S08006. doi:10.1029/2006SW 000271

Jayachandran PT, Langley RB, MacDougall JW, Mushini SC, Pokhotelov D, Hamza AM, Mann IR, Milling DK, Kale ZC, 
Chadwick R, Kelly T, Danskin DW, Carrano CS (2009) The Canadian high arctic ionospheric network (CHAIN). Radio Sci 44:RS0A03. doi:10.1029/2008 RS004046

Jin SG, Komjathy A (2010) GNSS reflectometry and remote sensing: new roles and progresses. Adv Space Res 46(2):111-117

Komjathy A, Armatys M, Master D, Axelrad P, Zavorotn V, Katzberg S (2004) Retrieval of ocean surface wind speed and wind direction using reflected GPS signals. J Atmos Oceanic Technol 21(3):515-526

Lakakis K, Charalampakis M, Savaidis P (2009a) A spacial decision support system for highway infrastructure. Fifth international conference on construction in the 21 st century (CITC-V), Collaboration and Integration in Engineering, Management and Technology, 20-22 May, Istanbul, pp 1-8

Lakakis K, Charalampakis M, Savaidis P (2009b) A landslide definition by an integrated monitoring system. Fifth international conference on construction in the 21 st century (CITC$\mathrm{V})$, Collaboration and Integration in Engineering, Management and Technology, 20-22 May, Istanbul, pp 1-8

Lehmann M, Reiterer A (2008) Case-based deformation assessment - a concept. In: Reiterer A, Egly U (eds) Application of artificial intelligence in engineering geodesy. In: Proceedings of the first workshop on AIEG 2008, pp 91-98. http://info. tuwien.ac.at/ingeo/Downloads/AIEG2008_Proceedings.pdf

Lehmann M, Reiterer A, Kahmen H (2007) Deformation classification in high density point clouds. Optical 3-D measurement techniques VIII, vol. I, Zurich

Li ZW, Ding XL, Huang C, Wadge G, Zheng DW (2006) Modeling of atmospheric effects on InSAR measurements by incorporating terrain elevation information. J Atmos Solar Terr Phys 68:1189-1194

Martin-Neira M (1993) A passive reflectometry and interferometry system (PARIS): application to ocean altimetry. ESA J 17(4):331-355

Mayer C, Jakowski N (2009) Enhanced E-layer ionization in the auroral zones observed by radio occultation measurements onboard CHAMP and Formosat-3/COSMIC. Ann Geophys 27:1207-1212

Mentes G (2008a) Investigation of different possible agencies causing landslides on the High Loess Bank of the River Danube at Dunaföldvár, Hungary. In: Proceedings of the measuring the changes, 13th FIG international symposium on deformation measurements and analysis, 4th IAG symposium on geodesy for geotechnical and structural engineering, LNEC, Lisbon, CD, 12-15 May, pp 1-10

Mentes G (2008b) Investigation of micro-movements by borehole tiltmeters on the High Loess Bank of the River Danube at Dunaföldvár in Hungary. In: Proceedings of the INGEO 2008 - 4th International conference on engineering surveying, Slovak University of Technology, Bratislava, ISBN 978-80-227-2971-0, p 11

Ng AH, Chang H, Ge L, Rizos C, Omura M (2008) Radar interferometry for ground subsidence monitoring using ALOS PALSAR data. In: Proceedings of the XXI congress,
The International Society for Photogrammetry and Remote Sensing, Beijing, 3-11 July 2008

Nievinski FG (2009) Ray-tracing options to mitigate the neutral atmosphere delay in GPS. Technical Report No. 262, Department of Geodesy and Geomatics Engineering, Fredericton, NB

Nilsson T, Davis JL, Hill EM (2009) Using ground-based GPS to characterize atmospheric turbulence. Geophys Res Lett 36:L16807. doi:10.1029/2009 GL040090

Reiterer A, Egly U (eds) (2008) Application of artificial intelligence in engineering geodesy. In: Proceedings of the first workshop on AIEG 2008, 116 pp. http://info.tuwien.ac.at/ ingeo/Downloads/AIEG2008_Proceedings.pdf

Rius A, Aparicio JM, Cardellach E, Martin-Neira M, Chapron B (2002) Sea surface state measured using GPS reflected signals. Geophys Res Lett 29(23). doi:10.1029/ 2002GL015524

Rohm W, Bosy J (2009) Local tomography troposphere model over mountains areas. Atmos Res 93:777-785

Schmidt M, Bilitza D, Shum CK, Zeilhofer C (2007) Regional 4-D modeling of the ionospheric electron content. Adv Space Res. doi:10.1016/j.asr.2007.02.050

Schmidt M, Karslioglu MO, Zeilhofer C (2008) Regional multidimensional modeling of the ionosphere from satellite data. In: Proceedings of the TUJK annual scientific meeting, 14-16 Nov 2008, Ankara

Schön S, Brunner FK (2008) Atmospheric turbulence theory applied to GPS carrier-phase data. J Geod 82:47-57

Todorova S, Hobiger T, Schuh H (2008) Using the global navigation satellite system and satellite altimetry for combined global ionosphere maps. Adv Space Res 42:727-736. doi:10.1016/j.asr.2007.08.024

Újvári G, Mentes G, Theilen-Willige B (2008) Detection of landslide prone areas on the basis of geological, geomorphological investigations - a case study. In: Proceedings of the measuring the changes, 13th FIG International symposium on deformation measurements and analysis, 4th IAG symposium on geodesy for geotechnical and structural engineering, LNEC, Lisbon, CD, 12-15 May 2008, pp 1-9

Újvári G, Mentes G, Bányai L, Kraft J, Gyimóthy A, Kovács J (2009) Evolution of a bank failure along the River Danube at Dunaszekcsô, Hungary. Geomorphology 109:197-209. doi:10.1016/j.geomorph.2009.03.002

Urquhart L, Santos MC, Nievinsk FG (2011) Fitting of NWM Ray-traced slant factors to closed-form tropospheric mapping functions. In: Kenyon $\mathrm{S}$ et al (eds) Geodesy for planet earth. Springer, Heidelberg

Wickert J, Schmidt T, Michalak G, Heise S, Arras C, Beyerle G, Falck C, König R, Pingel D, Rothacher M (2009) GPS radio occultation with CHAMP, GRACE-A, SAC-C, TerraSAR$\mathrm{X}$, and FORMOSAT-3/COSMIC: brief review of results from GFZ. In: Steiner AK, Pirscher B, Foelsche U, Kirchengast G (eds) New horizons in occultation research. Springer, Berlin, pp 3-15. doi:10.1007/978-3-642-00321-9 